\title{
Estimation of relative exposure of dolphins to fishery activity
}

\author{
Frederick I. Archer*, Jessica V. Redfern, Tim Gerrodette, Susan J. Chivers, \\ William F. Perrin
}

Southwest Fisheries Science Center, 3333 North Torrey Pines Court, La Jolla, California 92037, USA

\begin{abstract}
For the past half-century, the purse seine fishery for yellowfin tuna has been a significant factor in the lives of dolphins in the eastern tropical Pacific (ETP). However, little is known about how frequently an individual dolphin is exposed to the fishery, and there are no methods available for accurately assessing the prior exposure of dolphins encountered at sea. Here we present a method to estimate an index of exposure based on a model of dolphin movement derived from data collected from multiple tracking studies. Based on this movement model, the method weights purse seine sets given their distance from a particular school of dolphins sighted at sea and how long ago they occurred. The method also takes into account the species composition and school size in the set. As a demonstration, we use the method to examine the spatial and temporal distribution of this index over an $11 \mathrm{yr}$ period for which we have detailed data on purse seine sets. While the method has been designed for examining exposure to the ETP purse seine fishery, it is also applicable to studies of other anthropogenic effects where there is concern about exposure rates, such as underwater sound, pollution, or ship strikes.
\end{abstract}

KEY WORDS: Fishery exposure $\cdot$ Dolphin $\cdot$ Eastern tropical Pacific

\section{INTRODUCTION}

Since the late 1950s, a large commercial purse seine fishery in the eastern tropical Pacific (ETP) has exploited the association of large schools of dolphins with yellowfin tuna Thunnus albacares by chasing and encircling the dolphins to capture the tuna below (National Research Council 1992, Gerrodette 2002). Historically, many dolphins, predominantly pantropical spotted Stenella attenuata and spinner S. longirostris dolphins, were killed during fishery operations (Wade 1994); however, modifications to fishing gear and practices in the 1970s and 1980s led to a drastic reduction in the number of dolphins killed in each set (IATTC 2009). Dolphin populations are not recovering at expected rates (Gerrodette \& Forcada 2005, Wade et al. 2002), and several recent studies have suggested that the experience dolphins in some populations have of being repeatedly chased, captured, and released may have negative effects on survival or reproduction through a variety of possible factors, such as separation of mothers and calves (Archer et al. 2001, Edwards 2006), or a decrease in calf production or the length of time calves spend nursing (Cramer et al. 2008).

From 1998 to 2007, there were 11000 dolphin sets $\mathrm{yr}^{-1}$ in the ETP purse seine fishery (IATTC 2009). Although this estimate provides an aggregate measure of the impact of the fishery on dolphins, it does not encapsulate spatial or temporal variation in intensity of fishery activity. Current population estimates of the management stocks most frequently involved in the fishery are $\sim 860000$ (coefficient of variation $[\mathrm{CV}]=$ $23 \%$ ) for northeastern spotted Stenella attenuata attenuata, and $\sim 1100000$ (CV $=26 \%$ ) for eastern spinner $S$. longirostris orientalis dolphins (Gerrodette et al. 2008). On average, there are $\sim 120(\mathrm{CV}=17 \%)$ northeastern spotted dolphins and $\sim 200(\mathrm{CV}=15 \%)$ eastern spinners in a school (Gerrodette et al. 2008). Thus, if sets were randomly spread in space and time, then a 
given dolphin might be exposed to 1 to 2 sets $\mathrm{yr}^{-1}$. On the one hand, the stress related to chase, capture, and release (Curry 1999) might be relatively low across the population for an event that occurs this infrequently. On the other hand, if sets were spatially and temporally more concentrated such that a subset of the population experienced them relatively more frequently, there is a strong potential for multiple acute stress episodes to occur and lead to a general state of prolonged chronic stress along with associated negative physiological effects. To evaluate the potential magnitude of any of these effects on the population level, the frequency at which dolphins are exposed to purse seine operations needs to be quantified.

Perkins \& Edwards (1999) estimated annual set frequency by comparing the size distributions of schools that were set on to schools observed during research cruises. Because larger schools tend to carry more tuna, they are preferentially targeted by the fishery. For the school sizes most likely to be set on, it was estimated that sets occur between 2 and 8 times $\mathrm{yr}^{-1}$. The problem with extrapolating these results to the population is that we have very little information about how dolphin schools are structured and how individuals move among schools of different sizes. If these large schools are the result of ecological heterogeneity, and individuals randomly move in and out of them as the 'fission-fusion' model suggests (Perrin et al. 1979, Scott \& Cattanach 1998), the average annual capture rate of any given dolphin is likely to be on the low end of the estimates given by Perkins \& Edwards (1999). Conversely, stability of school membership or demographic structuring would tend to increase the frequency of sets for some individuals to values closer to the high end of these estimates.

Mesnick et al. (2002) found that fishery exposure was significantly correlated to short-term evasive behavior for those stocks most frequently set on in the ETP. In their study, fishery exposure for individual dolphin sightings was estimated by counting the number of sets occurring within a specified time and distance window (an 'ambit'). While it serves as a convenient summary metric of likely set activity around a sighting, this simple count may not accurately summarize the recent exposure that individuals may have had to the fishery. Using this method, sets on either the temporal or spatial periphery of the ambit will contribute as much to the metric as sets close to the sighting, although they have a lower chance of having been encountered by dolphins in that sighting. Likewise school size and stock composition were not taken into account; consequently sets on small schools are weighted equally with sets on large schools, and sets that are not on the species of interest contribute to the metric.
Here we present a method that overcomes these shortcomings and measures relative fishery exposure for any given location and time (such as for a dolphin or dolphins encountered at sea, which we refer to as a 'sighting') by weighting sets based on a model of spotted dolphin movement derived from empirical tracking and mark/recapture data. As an example of the type of study that can be conducted with this algorithm, we also present an examination of the spatial and temporal patterns of exposure for 3 species of dolphins involved in the ETP tuna purse seine fishery. The applicability of this method is not limited to this problem or region. By replacing a field of purse seine sets with any other anthropogenic effect such as underwater sound sources, pollution outflows, or vessel traffic, the method can easily be extended to studies of other types of potentially harmful exposure.

\section{MATERIALS AND METHODS}

The exposure index that we have developed is based on a model of dolphin movement derived from empirical data. This model produces a probability distribution for a dolphin travelling a given distance in a specified amount of time, which we use to weight purse seine sets occurring in the vicinity of dolphins sighted at sea. In addition, the size and species composition of the dolphin schools involved in the set are used in the weighting scheme. The weights for each set are summed to produce the final index of exposure. In the following, we detail how each component of the index is calculated.

Dolphin movement model. The data used to model dolphin movement were collected during a tagging project conducted from 1969 to 1978 (Perrin et al. 1979, Hedgepeth 1985) and a radio-tracking study conducted from 1992 to 1993 and in 2001 (Scott \& Chivers 2009). In the tagging study, technicians onboard purse seiners attached a variety of tags, most of which were 'spaghetti' tags, to dolphins as they were released from the net. Biological data on the dolphin and information about the tagging event, such as tag type, tag number, location, and date were recorded on release. If the tagged dolphins were subsequently resighted or recaptured, the date and location were recorded.

In the radio-tracking study, focal spotted dolphins were captured by a purse seiner and fitted with radiotransmitters. These dolphins were then followed for up to $3 \mathrm{~d}$ and recaptured by the purse seiner as part of a larger study designed to examine their blood chemistry for evidence of stress-related changes (Forney et al. 2002). Because the data from these dolphins indicated rapid straight-line swimming immediately after release that was likely due to escape from the area of 
the tagging operation, we selected the position and time $1 \mathrm{~h}$ after release to be the initial point of normal movement (Scott \& Chivers 2009). The end point for the track was the position and time immediately preceding the initiation of the chase for recapture. After their first recapture, 2 dolphins were released with the radio-transmitter still attached and captured again at a later point. These multiple capture/recaptures from the same dolphin were used in the analysis, with each pair used as an independent time/distance point. In total, 31 tracks were available from 29 dolphins tracked in this study.

For this analysis, the tagging and tracking datasets described above were combined. We used only 1 sample when multiple dolphins were released and resighted in the tagging dataset. To avoid potentially confounding variation due to annual movement patterns of both dolphins and the tuna purse seiners that collected resight and recapture data (Perrin et al. 1979), we restricted samples in the analysis to those animals recaptured within half a year (183 d). One outlying tag return of 1608 nautical miles (n miles) in $107 \mathrm{~d}$ was removed from the analysis. The final sample size from the combined datasets was 146 tracks, or pairs of release and resight/recapture points.

We modeled the relationship between dolphin travel distance and time using a standard random walk model (Pielou 1969, Okubo 1980, Gerrodette 1981). For diffusing particles with no directional movement, the distance traveled, $x$, from a point of origin is described by a power function of the form

$$
x=a \times t^{b}
$$

where $a$ is a positive proportionality constant, and time $t$ is raised to the power $b$ which determines the diffusion rate, defined as a positive real value in a random walk model. In our data, the distance traveled $(x)$ was calculated as the great circle distance between release and recapture locations in $\mathrm{n}$ miles, and time at liberty $(t)$ was calculated to the nearest minute.

We estimated the parameters of the random walk model using a Bayesian analysis of the movement data. The likelihood function was based on a normal distribution using a log-transform of Eq. 1, which converts the power function to a linear function,

$$
\log (x) \sim N\left(a^{\prime}+b \times \log (t), \tau\right)
$$

where $a^{\prime}$ is $\log (a)$, and $\tau$ is the precision, or the inverse of the variance $\left(\sigma^{2}\right)$. Priors for $a^{\prime}, b$ were $\operatorname{Uniform}(0,10)$, and $\tau$ was Gamma(shape $=10^{-3}$, rate $\left.=10^{-3}\right)$. Six independent Markov chain Monte Carlo (MCMC) chains were run, with each chain initialized from random draws from the prior distributions. A burn-in period of 10000 updates was conducted for each chain, followed by another 100000 updates. Every 100th update was saved to produce a total of 1000 samples from each chain. The 6000 samples from all chains were then combined to create a single sample from the final posterior probability distribution for $a^{\prime}, b$, and $\sigma^{2}$. The analysis was conducted using the package BRugs v0.51 running OpenBUGS v3.0.3 on R v2.9.0 (R Development Core Team).

Using the joint posterior distribution on the parameters from the above Bayesian model, the probability distribution that a dolphin would have traveled $x$ $\mathrm{n}$ miles in $t \mathrm{~d}$ is given as

$$
\operatorname{Pr}\left(x \mid t, a^{\prime}, b, \sigma^{2}\right)=\frac{1}{\sqrt{2 \pi \sigma^{2}}} \cdot \mathrm{e}^{-\left[\frac{\left(\log (x)-\left(a^{\prime}+b \cdot \log (t)\right)\right)^{2}}{2 \sigma^{2}}\right]}
$$

Exposure index. The exposure index for a given dolphin sighting is best visualized as a weighted sum of purse seine sets that have occurred prior to that sighting. The first component of the weighting scheme is the probability that a dolphin from the sighting was involved in each set. A set is assumed to have a region of influence, represented by a circle around its reported location. For this study, circles of 2 radii were examined: $6 \mathrm{n}$ miles, representing the average distance to the horizon for a visual observer, and $12 \mathrm{n}$ miles, representing the average detection distance of the onboard 'bird' radar (M. Scott pers. comm.). Thus, the probability that a dolphin was exposed to a set is

$$
\operatorname{Pr}\left(\operatorname{exposure}_{i}\right)=\int_{j} \operatorname{median}\left(\operatorname{Pr}\left(x_{j} \mid t_{i}\right)\right)
$$

where $j$ represents all points within the set circle, $x$ is the distance from any given point to the sighting, and $t_{i}$ is the time elapsed between the set and the sighting in minutes. For this study, we used the time recorded as the beginning of the chase to represent the time the set occurred.

As the distance between a sighting and a set increases, the probability that a dolphin in that sighting was exposed to that set decreases, not only according to Eq. 3. It also decreases because the dolphin could have travelled to the sighting location from an increasingly larger area. Specifically, the set makes up a smaller fraction of the area that the dolphin could have inhabited in the past. Consequently, we also weight a set by the fraction of the area around the sighting it occupies

$$
W_{i}=\frac{A\left(\text { set }_{i}\right)}{A\left(\text { extent }_{i}\right)}
$$

where extent ${ }_{i}$ is defined as a circle around the sighting of radius $d+r$, where $d$ is the distance from the sighting to the set center, and $r$ is the set radius (Fig. 1). If the set circle or set extent intersected the coastline, only the area over water was used in the above calculation. 


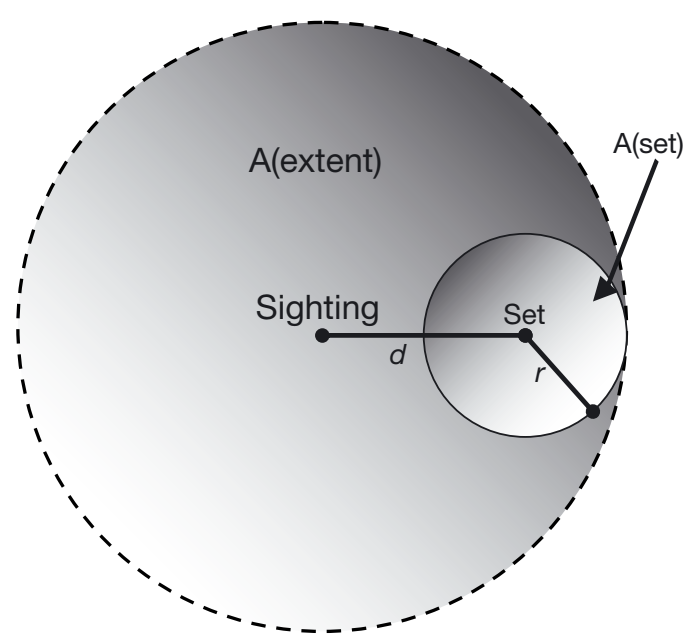

Fig. 1. Set area, $A($ set), and extent area, $A$ (extent), for Eq. 5 in text (see 'Materials and methods'), where $d$ is the distance from the dolphin sighting to the set and $r$ is the search radius of the set

The final component of the exposure index weighting is the species-specific group size of dolphins in the set $\left(\right.$ Nspecies $\left._{i}\right)$. For example, all other things being equal, an eastern spinner dolphin is 10 times more likely to have been involved in a set where 200 spinners were chased than in a set with 20 spinners. Conversely, the exposure index for a set with no spinners chased should be 0 regardless of its distance and temporal proximity to a spinner sighting.

To simplify calculations, we limited the number of sets considered around a sighting to those occurring within $60 \mathrm{~d}$ and the upper 95th percentile of the estimated distance a dolphin could travel within $60 \mathrm{~d}$ ( $\approx 481 \mathrm{n}$ miles). Thus, for a sighting with $k$ sets in this ambit, the exposure index for a sighting of a given species is

Index $\left(\right.$ sight $\left._{\text {species }}\right)=\sum_{i=1}^{k}\left(\operatorname{Pr}\left(\operatorname{exposure}_{i}\right) \times W_{i} \times\right.$ Nspecies $\left._{i}\right)$

Spatial and temporal exposure analyses. We examined the spatial and temporal distribution of the exposure index for the 3 dolphin species most commonly involved in the ETP tuna purse seine fishery: offshore spotted dolphins, eastern spinner dolphins, and pooled northern, central, and southern stocks of short-beaked common dolphins Delphinus delphis. Offshore spotted dolphins are composed of 2 management stocks (northeastern and western/southern; Perrin 1990, Dizon et al. 1994), and common dolphins are composed of 3 stocks (northern, central, and southern; Perrin et al. 1985). In all analyses, data for these stocks were combined. To estimate the exposure for each species, we multiplied the exposure index for that species by an estimate of its density for each day of survey effort on research cruises conducted by the Southwest Fisheries Science Center from 1979 to 1990 (Table 1). These years were selected because we had access to detailed data on the position, time, and dolphin composition of tuna purse seine sets for a significant portion of the fleet, as described below.

For each survey day in which there were at least $10 \mathrm{n}$ miles of survey effort ( $1 \mathrm{~h}$ of effort), the density of a species was estimated as

$$
\text { Density (species) }=\frac{\sum S_{\text {species }} \times f(0)_{\text {species }}}{2 \times e \times g(0)_{\text {species }}}
$$

where $S$ is the group size of each sighting of that species, estimated from the average of the 'best' estimates provided by observers. If no 'best' estimates were made, the observers' 'low' estimate was used. If a sighting was composed of multiple species, speciesspecific group sizes were calculated as the average of each observer's estimate multiplied by their estimate of the percentage of individuals of that stock. Only sightings made while on-effort (sensu Kinzey et al. 2000) were used in the calculation. Effort (e) is the linear distance covered while on-effort each day. The line-transect variables, $f(0)$ and $g(0)$, respectively correct for decreasing detection probabilities with distance from the transect and failure to detect all animals on the transect (Buckland et al. 2001). Species-specific $f(0)$ and $g(0)$ values were taken from Ferguson \& Barlow (2001). We did not subsample data to account for sea state constraints in Ferguson \& Barlow (2001), but applied the $f(0)$ and $g(0)$ values to all data, which may negatively bias densities estimated in sea states higher than Beaufort 5. For spotted and common dolphins, multiple values of $f(0)$ and $g(0)$ for different stocks in the ETP were averaged. Details of survey methodology

Table 1. Southwest Fisheries Science Center research cruises conducted in the eastern tropical Pacific used to estimate daily density. PPAS: Porpoise Population Assessment Survey; MOPS: Monitoring of Porpoise Stocks

\begin{tabular}{|llcc|}
\hline Year & Cruise name & $\begin{array}{c}\text { Ships } \\
\text { (n) }\end{array}$ & $\begin{array}{c}\text { On effort } \\
\text { days (n) }\end{array}$ \\
\hline 1979 & PPAS & 2 & 120 \\
1980 & PPAS & 2 & 108 \\
1982 & PPAS & 1 & 66 \\
1983 & PPAS & 1 & 78 \\
1986 & MOPS & 2 & 198 \\
1987 & MOPS & 2 & 198 \\
1988 & MOPS & 2 & 185 \\
1989 & MOPS & 2 & 202 \\
1990 & MOPS & 2 & 210 \\
\hline
\end{tabular}




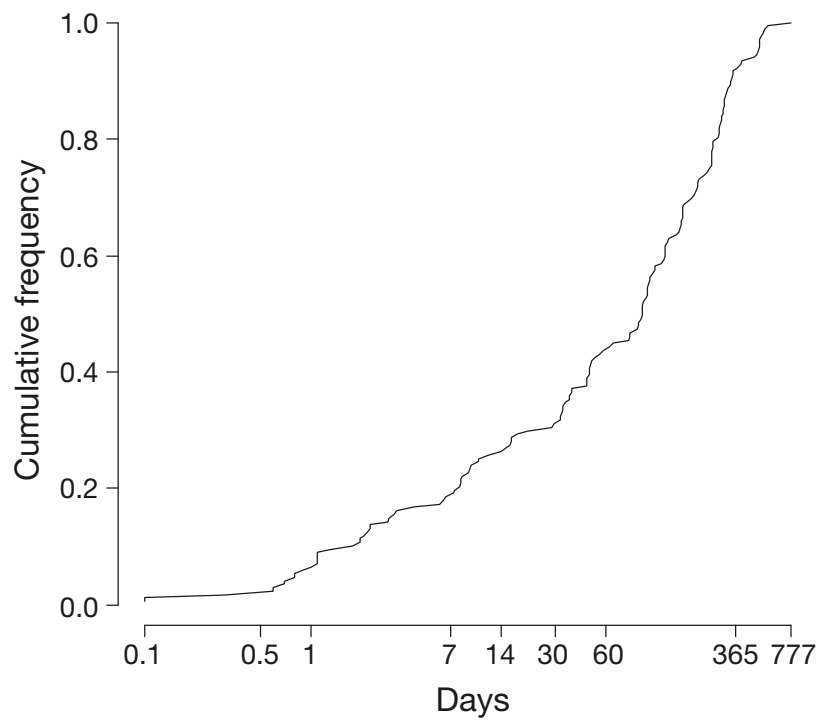

Fig. 2. Cumulative frequency distribution of number of days between release and recapture for 214 dolphins tagged between 1969 and 1978. $x$-axis is log-scaled

can be found in Kinzey et al. (2000) and Gerrodette \& Forcada (2002) and references therein. For the exposure index calculation, the location chosen for each day with a density estimate was the position of the ship at noon, and the time used was 23:59:59 local time, to ensure all sets occurring on that day were included in the calculations.

Set data were extracted from the US National Marine Fisheries Service (NMFS) tuna purse seine observer database (described by Edwards 1989) covering US fleet activity from 1971 to 1990. Set times were recorded to the nearest minute and locations to the nearest degree. Dolphin school size was taken as the observer's best estimate prorated by the percent composition of spinner, spotted, or common dolphins in the school.

Spatial and temporal patterns were interpolated with inverse distance weighting (IDW) as implemented in the gstat package in R. The IDW power factor was 0.8 for all analyses. Spatial grid sizes were 0.5 degrees of latitude and longitude. Monthly grids were used for temporal scales.

\section{RESULTS}

\section{Dolphin movement}

Over the $11 \mathrm{yr}$ of the mark-recapture project, 4267 tags were deployed and 214 were opportunistically recovered from dolphins killed during sets or resighted on dolphins released from the net (Hedgepeth 1985).
An examination of the distribution of the time to recapture for these tags (Fig. 2) shows that $~ 93 \%$ occurred within $1 \mathrm{yr}, 35 \%$ within $1 \mathrm{mo}, 22 \%$ within $1 \mathrm{wk}$, and $8 \%$ within $1 \mathrm{~d}$. The median time to recapture was $95 \mathrm{~d}$. Converted to an annual rate, the median of this distribution is 3.7 captures $\mathrm{yr}^{-1}$ with a central inter-quartile range of 1.4 to 33 captures $\mathrm{yr}^{-1}$.

The joint posterior distribution of the parameters $a^{\prime}$ and $b$ from the Bayesian movement model (Eq. 2) shows that the 2 are negatively correlated as expected for the intercept and slope parameters of a linear model (Fig. 3). Both parameters were uncorrelated with $\sigma$. Diagnostics of the MCMC chains indicate that there was good mixing after the burn-in period and there was no significant autocorrelation after a lag of 2 (data not shown). The probability distribution of movement (Fig. 4, from Eq. 3) broadens rapidly within the first week, such that after $7 \mathrm{~d}$, a dolphin is most likely to be $\sim 60 \mathrm{n}$ miles from its point of origin, with a $95 \%$ highest posterior density (HPD) interval of 16 to $223 \mathrm{n}$ miles. After $30 \mathrm{~d}$, the most likely distance is $117 \mathrm{n}$ miles with a $95 \% \mathrm{HPD}$ of 31 to $433 \mathrm{n}$ miles.

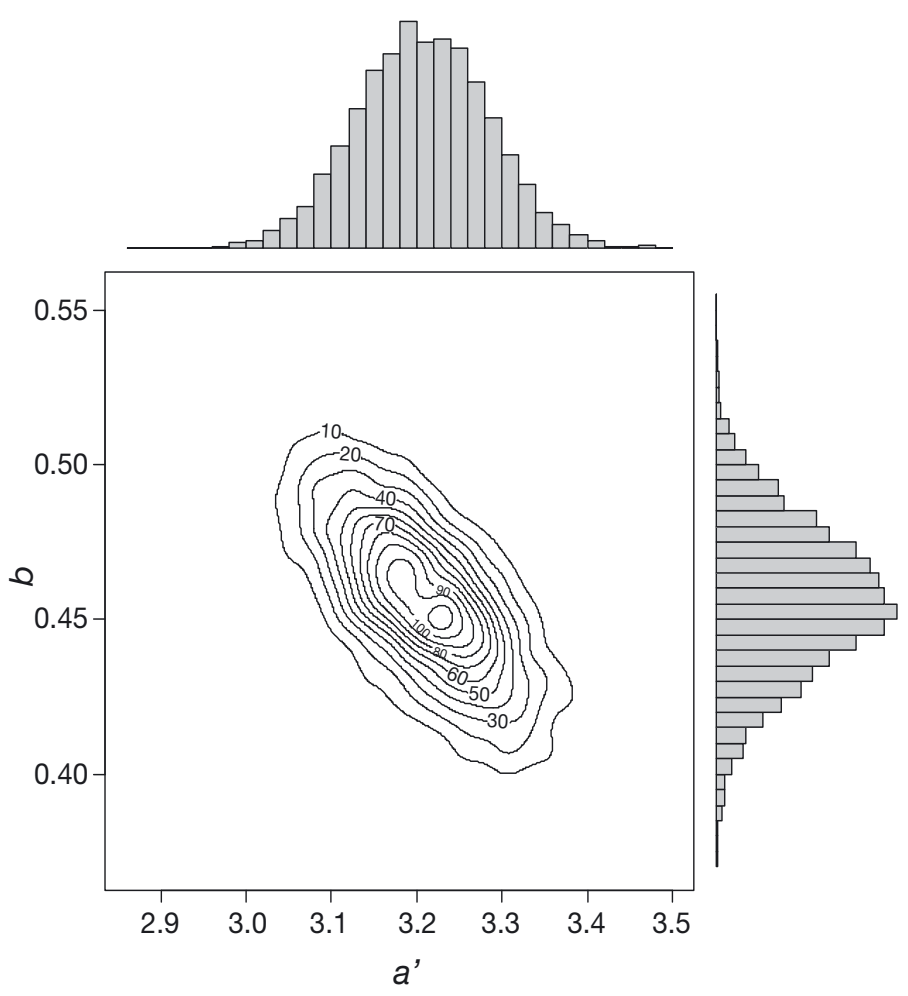

Fig. 3. Contour of joint posterior distribution of $a^{\prime}$ and $b$ parameters from the dolphin movement model with marginal histograms along respective axes. Area under histograms sums to total number of samples from the posterior chain distribution $(\mathrm{n}=6000)$. Values in contour are frequency of samples from Markov chain Monte Carlo (MCMC) chains 


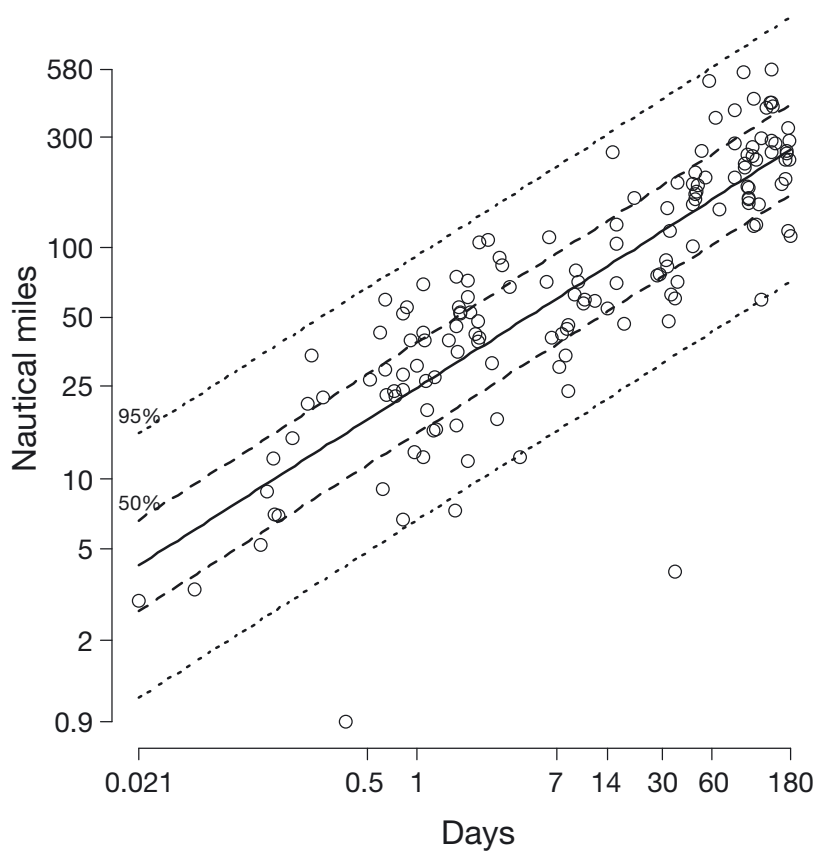

Fig. 4. Fit of Bayesian model to movement data from tagged dolphins. Both axes log-scaled. Lines: solid = median, dashed $=$ central $50 \%$, dotted $=$ central $95 \%$ of posterior fit exposure index for the 3 species was 64.6 for spotted dolphins, 15.6 for spinner dolphins, and 1.65 for common dolphins.

\section{Spatial and temporal exposure analyses}

The spatial and temporal distribution of the exposure index weighted by density is given in Fig. 6. Exposure of common dolphins to the US tuna purse seine fishery was highest along the coast of Central America, remaining high but decreasing in intensity southward along the coasts of Colombia, Ecuador, and northern Peru (Fig. 6a). Exposure in this area for common dolphins was relatively low in the late 1970s as indicated by the blue region in Fig. $6 \mathrm{~b}$ from $\sim 0^{\circ}$ to $\sim 20^{\circ} \mathrm{N}$, increasing to its peak in the late 1980 s along this band. There is a stronger east-west gradient of exposure for this species (Fig. 6c), with very low values west of $\sim 100^{\circ} \mathrm{W}$. Exposure east of this line also increases over time, peaking around $90^{\circ} \mathrm{W}$ in 1990 .

For both eastern spinner and offshore spotted dolphins, exposure was greatest in the core of the ETP (Fig. $6 \mathrm{~d}, \mathrm{~g}$ ), between $\sim 10^{\circ}$ and $\sim 20^{\circ} \mathrm{N}$, around $100^{\circ} \mathrm{W}$. There is evidence of a latitudinal shift in exposure for these 2 species in which the center of fishery exposure in the late $1970 \mathrm{~s}$, which was at $\sim 15^{\circ} \mathrm{N}$, shifted $\sim 5^{\circ}$ far-

\section{Exposure index}

Daily density was estimated for $1365 \mathrm{~d}$ of effort during 10 cruises from 1979 to 1990 (Fig. 5). Most survey effort occurred close to the coast of Central America and offshore to about $120^{\circ} \mathrm{W}$, between $20^{\circ} \mathrm{N}$ and the equator. The ambit around each day was defined as a circle of $481 \mathrm{n}$ miles and the previous $60 \mathrm{~d}$, the same spatial and temporal limits placed on sets used in calculating the exposure index. For these days, the median number of sets within this ambit was 12. Approximately $30 \%$ of the days $(n=404)$ had no sets in the ambit. The maximum number of sets in an ambit was 295.

For all species, the distribution of the daily exposure index was heavily skewed towards 0. Specifically, exposure indices were 0 for 70,87 , and $96 \%$ of the days for offshore spotted, eastern spinner, and common dolphins, respectively. These indices represent both cases with 0 sets on the species in the ambit and days when the species was not sighted (density estimate $=0$ ). The maximum

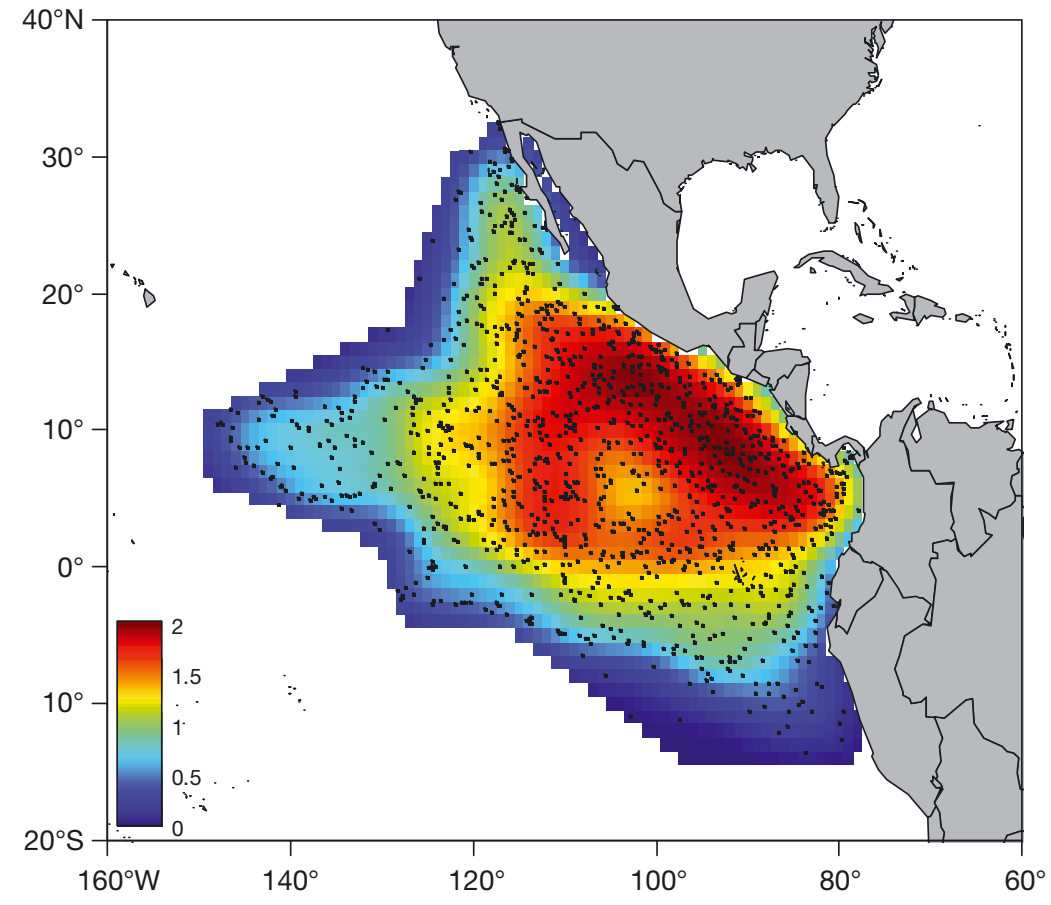

Fig. 5. Locations of days of survey effort in the eastern tropical Pacific (ETP) from 1979 to 1990. Color scale is a 2D kernel density smoother estimate of the number of points representing $1 \mathrm{~d}$ of survey effort within a $1^{\circ}$ square area. Some overlap of points occurs in areas of high effort (red) 

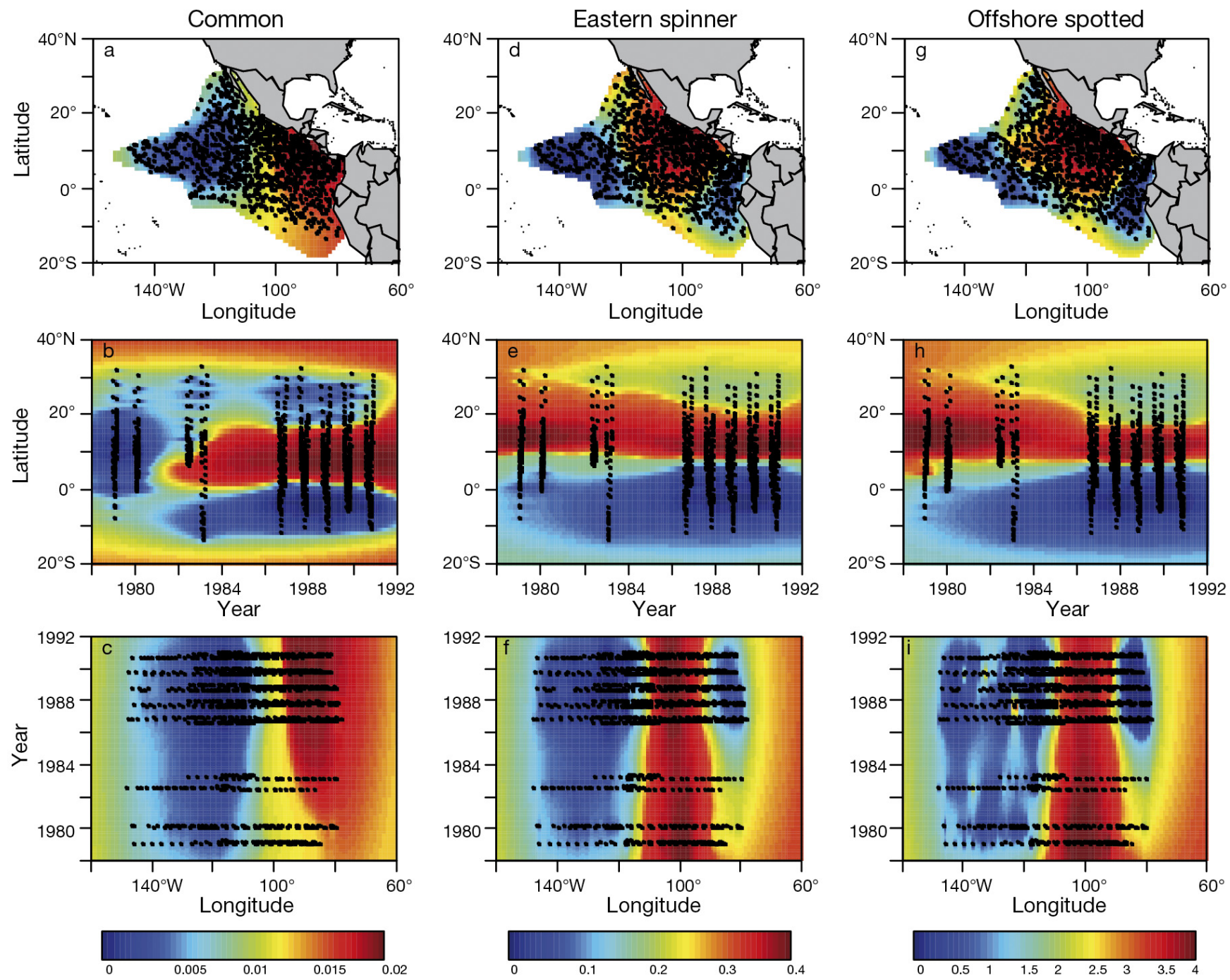

Fig. 6. Delphinus delphis, Stenella longirostris and S. attenuata. Inverse distance weighted smoothed distributions of exposure indices weighted by daily density for $(\mathrm{a}-\mathrm{c})$ common, $(\mathrm{d}-\mathrm{f})$ eastern spinner, and $(\mathrm{g}-\mathrm{i})$ offshore spotted dolphins. First row: spatial distribution. Second row: distribution of latitude by year. Third row: distribution of longitude by year. Values range from minimum (blue) to maximum (red) within a species (color scale for each column is given on bottom row)

ther south by the late 1980s (Fig. 6e,h). During this time frame, there is also westward shift of exposure for eastern spinners from $\sim 100^{\circ}$ to $\sim 105^{\circ} \mathrm{W}$ (Fig. 6f), which is not as evident in the plot for offshore spotted dolphins (Fig. 6g). Additionally, exposure was relatively low for both spotted and spinner dolphins along the coasts of Colombia and Ecuador (Fig. 6d,g).

\section{DISCUSSION}

We present a new method of quantifying the exposure of dolphins to the tuna purse seine fishery using an algorithm that weights purse seine sets based on the time and distance at which they occurred, their species composition, and a model of dolphin movement. The result is an index in which sets with more dolphins or those that occurred closer in time or space have more influence, thus measuring relatively 'recent' exposure to the fishery. The necessity for this algorithm stems from a need to estimate exposure on a finer temporal and spatial scale than has been done previously to better examine the effects of repeated chase, capture, and release.

Comparing the distribution of the number of sets in the ambit and the exposure index for each species shows that the exposure index is not a simple monotonic function of the number of sets (Fig. 7). With few sets in an ambit, exposure is limited to relatively small values. As the number of sets increases, the potential for 

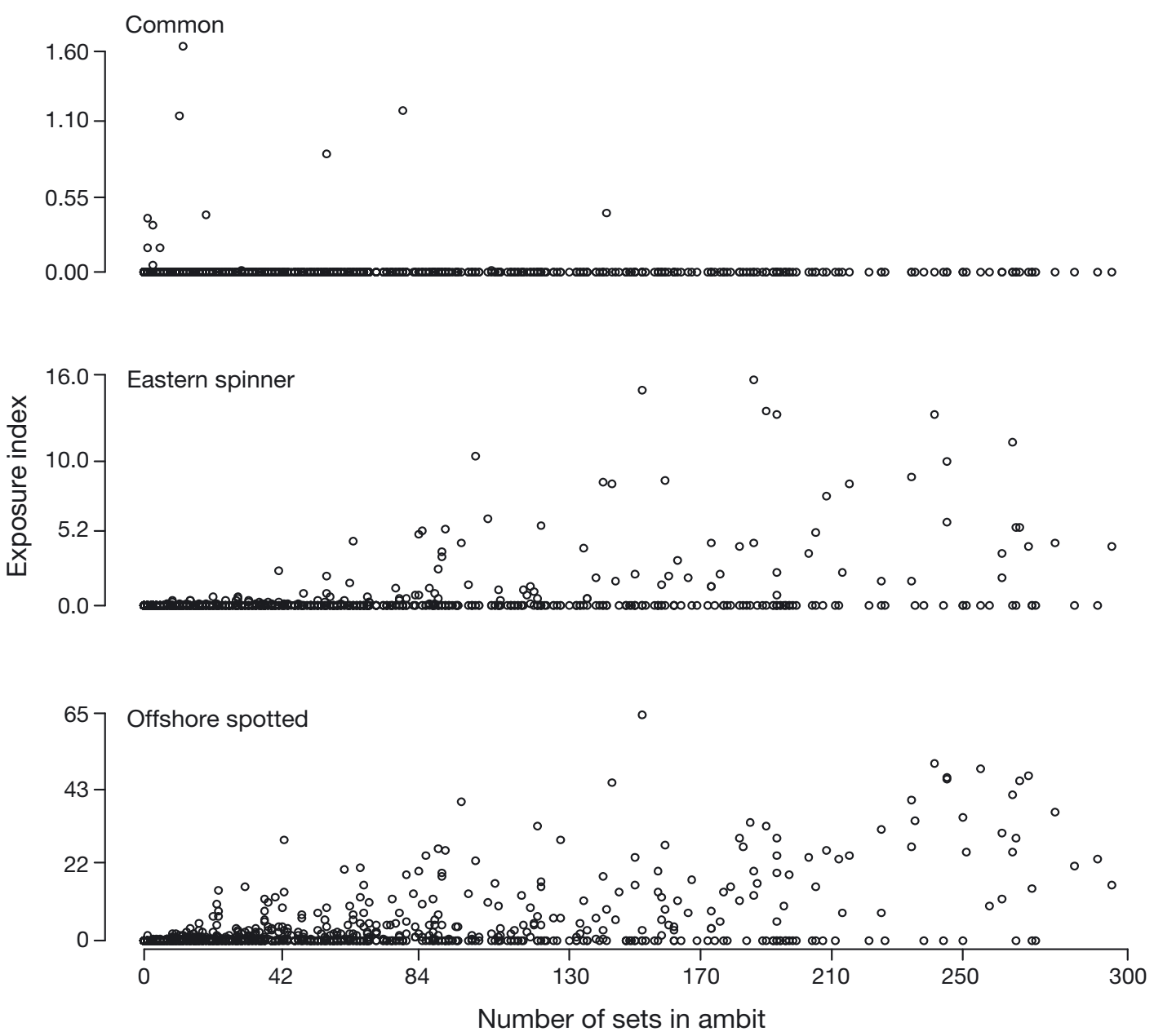

Fig. 7. Delphinus delphis, Stenella longirostris and S. attenuata. Relationship of exposure index to number of sets in ambit for days of survey effort

exposure also increases, but can also remain at low levels. Even with several hundred sets in the ambit, exposure can be equal or close to 0 , indicating that either most of these sets occurred at a great temporal or spatial distance, or did not involve many dolphins of that particular species. The pattern seen for common dolphins reflects the fact that exposure was 0 for a large proportion of days for these species. However, although the maximum exposure for common dolphins is low relative to spotted and spinner dolphins, it is notable that days with non-0 exposure were based on relatively few sets in the ambit. This suggests that when common dolphins are set on, sets are relatively more concentrated in space and time. This result makes sense given the concentration of this species around the Costa Rica Dome, a highly productive upwelling region centered around $90^{\circ} \mathrm{W}, 10^{\circ} \mathrm{N}$ (Danil \& Chivers 2006).

It is clear that the ETP purse seine fishery has been a significant factor in the lives of dolphins since its inception (Gosliner 1999, Reilly et al. 2005, Edwards 2007).
One of the best indicators of its impact has been the relationship between dolphin evasiveness and fishery exposure (Schramm Urrutia 1997, Heckel et al. 2000, Mesnick et al. 2002, Lennert-Cody \& Scott 2005). In a review of historical observer data, Lennert-Cody \& Scott (2005) showed that the $\sim 40 \mathrm{yr}$ westward and southward movement of the fishery is correlated with an increase in evasiveness of spotted and spinner dolphins. The authors hypothesized that the cumulative exposure of dolphins triggers and maintains heightened evasive behaviors. Consequently, schools of highly evasive dolphins, including those labeled 'the untouchables' by fishermen (Pryor \& Norris 1978), become prevalent in regions that have been fished the longest.

These effects can also be seen over relatively short time frames. In a study of vessel response behavior of ETP dolphins during research cruises, Mesnick et al. (2002) found that the number of purse seine sets in the past $70 \mathrm{~d}$ and within $300 \mathrm{n}$ miles of each dolphin sight- 
ing is a significant predictor of whether that sighting will be evasive. However, this relationship only exists for those species frequently involved in purse seine fishing (spotted, spinner, and common dolphins). Species of other dolphins not involved in the fishery, and with varying degrees of 'natural' evasiveness, did not vary their evasive responses relative to prior fishery activity.

There is also evidence that the fishery is influencing reproduction in dolphin populations. Cramer et al. (2008) showed a significant negative relationship between the age at weaning of northeastern offshore spotted dolphins and the total number of dolphin sets made within 1 yr. The authors also suggested that previously observed differences in life history parameters between exploited and non-exploited management stocks (Perrin \& Henderson 1984, Barlow 1985, Chivers $\&$ Myrick 1993) are consistent with negative impacts of the fishery on reproduction.

Each year, there are 11000 purse seine sets made on dolphins in the ETP (IATTC 2009). However, little is known about how frequently an individual dolphin is likely to experience a set within a year. The only empirical data available come from the 1969 to 1980 study on seasonality of dolphin movement in the ETP from which we acquired the mark-recapture data used in constructing the movement model in this paper (Perrin et al. 1979, Hedgepeth 1985). From the distribution of these recaptures, the median time to recapture was $98 \mathrm{~d}$, which translates to $\sim 3.7$ captures $\mathrm{yr}^{-1}$.

However, several aspects of these data prevent us from treating these values as true estimates of set frequency for spotted dolphins. Tag designs used during the majority of this experiment limited recovery to only those dolphins that were killed during sets. Thus, there is no way to account for dolphins which were tagged, set on, and released, perhaps multiple times prior to their death, introducing a positive bias in our data. Specifically, for any of the tagged dolphins that were recovered, the true time to recapture has the potential of being less, but not greater, which would increase estimates of annual capture rate.

An additional bias may occur in these data because the tags were placed on dolphins captured as a result of routine fishing activities. Consequently, these results may not be applicable to the 'average' dolphin because they do not take into account the probability of being captured in the first place, which likely varies both temporally and spatially. To accurately model movement for the entire population, data would have to be randomly collected across the range of the stocks in question, both from dolphins set on as well as those not involved in sets.

It should be noted that the exposure index that we have presented also does not allow one to estimate actual set frequency. To convert it to set frequency, one would need some ground-truth data that would permit the correlation of the index with a known capture history. The advance that our method makes over other studies in the past is that it permits the calculation of a relative measure of set exposure for individual sightings of dolphins rather than aggregate measures over long time frames. As we have demonstrated here, this permits the examination of exposure on finer spatial and temporal scales than before.

While the spatial and temporal patterns of exposure agree with other analyses of these species during the same time frame (Lennert-Cody \& Scott 2005), the analysis presented here using the NMFS observers set database is only intended as an example of how the exposure index can be employed. Because the data in the NMFS database represent from 1 to $48 \%$ of all purse seine sets made on dolphins between 1971 and 1990 (Edwards 1989, IATTC 2009), it is not considered complete and may not fully reflect the true patterns and intensity of the ETP tuna fishery. During these years, especially after the mid-1980s, fishing by vessels from other nations, primarily Mexico, was increasing. Over the past couple of decades, this international fleet has progressively moved from nearshore central Mexico to offshore regions to the south and west (LennertCody \& Scott 2005). A comprehensive spatial and temporal analysis following the template we have outlined would require data on the location and time of non-US observed sets from the IATTC observer and logbook databases, which were unavailable to us at the time of this writing.

Several components of our model of dolphin movement could be improved if more data become available. Our model is essentially 1-dimensional because it assumes that directionality of travel is random (with the exception of coastal waters). Perrin et al. (1979) found that movement $<300 \mathrm{n}$ miles was essentially random, while movements $>300 \mathrm{n}$ miles tended to be along an east-west axis, although sample sizes at these distances were low. Thus, it is unlikely that there is significant directional movement on the time scale that we are interested in. However, it may be possible to address potential spatial heterogeneity by integrating this model with models designed to predict dolphin density based on habitat variables (Barlow et al. 2009).

Finally, it should be noted that the movement data available to us were primarily collected from northeastern and southern/western offshore spotted dolphins. Movement patterns of individuals in stocks of other species are likely to differ. For example, from their series of tagging and radio-tracking studies, Perrin (1975) and Perrin et al. (1979) suggested that eastern spinner dolphins exhibit less net movement than offshore spotted dolphins. Thus, a stock-specific model 
would require collecting sufficient movement data from each stock separately or exploring using habitatdensity models as mentioned above.

Although this index has been explicitly developed for estimating the exposure of dolphins to the ETP tuna purse seine fishery, the basic algorithm can easily be modified to examine the exposure of cetaceans to a variety of other events. For example, the effects of anthropogenic noise on cetaceans have been receiving an increased amount of interest in recent years (Romano et al. 2004, Cox et al. 2006, Nowacek et al. 2007). By collecting the location and times of the sound sources of interest and constructing a movement model for the species in question, one could assess the cumulative impact of repeated sounds on populations over a period of time and examine physiological or behavioral correlates in sampled individuals. Similarly, one could extend this kind of analysis to estimate exposure to other anthropogenic sources which may be stationary in space, but vary in time, such as pollution outflows, spills, or interactions with static fishing gear.

Acknowledgements. We thank A. Jackson for assistance with compiling the observer set data and cruise sighting data. M. Scott was instrumental in the experimental design and data collection for the radiotracking studies. L. Ballance participated in the development of the daily density estimations. We also thank N. Kellar, G. Watters, T. Eguchi, and J. Barlow for many helpful discussions and suggestions for improving the analysis and manuscript.

\section{LITERATURE CITED}

Archer F, Gerrodette T, Dizon A, Abella K, Southern S (2001) Unobserved kill of nursing dolphin calves in a tuna purse seine fishery. Mar Mamm Sci 17:540-554

Barlow J (1985) Variability, biases, and trends in reproductive rates of spotted dolphins, Stenella attenuata. Fish Bull 83:657-669

Barlow J, Ferguson MC, Becker EA, Redfern JV and others (2009) Predictive modeling of marine mammal density from existing survey data and model validation using upcoming surveys. NOAA Tech Memo NMFS-SWFSC444

Buckland ST, Anderson DR, Burnham KP, Laake JL, Borchers DL, Thomas L (2001) Introduction to distance sampling: estimating abundance of biological populations. Oxford University Press, Oxford

Chivers SJ, Myrick AC (1993) Comparison of age at sexual maturity and other reproductive parameters for two stocks of spotted dolphin, Stenella attenuata. Fish Bull 91: 611-618

Cox TM, Ragen TJ, Read AJ, Vos E and others (2006) Understanding the impacts of anthropogenic sound on beaked whales. J Cetacean Res Manag 7:177-187

Cramer KL, Perryman WL, Gerrodette T (2008) Declines in reproductive output in two dolphin populations depleted by the yellowfin tuna purse seine fishery. Mar Ecol Prog Ser 369:273-285

Curry BE (1999) Stress in mammals: the potential influence of fishery-induced stress on dolphins in the eastern tropical
Pacific Ocean. NOAA Tech Memo NMFS-SWFSC-260

Danil K, Chivers SJ (2006) Habitat-based spatial and temporal variability in life history characteristics of female common dolphins Delphinus delphis in the eastern tropical Pacific. Mar Ecol Prog Ser 318:277-286

Dizon AE, Perrin WF, Akin PA (1994) Stocks of dolphins (Stenella spp. and Delphinus delphis) in the eastern tropical Pacific: a phylogeographic classification. NOAA Tech Memo NMFS-SWFSC-119

Edwards EF (1989) Using tuna-vessel observer data to detect trends in abundance of dolphin populations: history and research to date (1988). NOAA Tech Memo NMFSSWFSC-122

Edwards EF (2006) Duration of unassisted swimming activity for spotted dolphin (Stenella attenuata) calves: implications for mother-calf separation during tuna purse seine sets. Fish Bull 104:125-135

Edwards EF (2007) Fishery effects on dolphins targeted by tuna purse seiners in the eastern tropical Pacific Ocean. Int J Comp Psychol 20:217-227

Ferguson MC, Barlow J (2001) Spatial distribution and density of cetaceans in the eastern tropical Pacific Ocean based on summer/fall research vessel surveys in 1986-96. NOAA Admin Rep LJ-01-04

Forney KA, St. Aubin DJ, Chivers SJ (2002) Chase encirclement stress studies on dolphins involved in eastern tropical Pacific Ocean purse-seine operations during 2001. NOAA Admin Rep LJ-02-32

> Gerrodette T (1981) Dispersal of the solitary coral Balanophyllia elegans by demersal planular larvae. Ecology 62:611-619

Gerrodette T (2002) Tuna-dolphin issue. In: Perrin WF, Würsig B, Thewissen H (eds). Encyclopedia of marine mammals. Academic Press, San Diego, CA, p 1269-1273

Gerrodette T, Forcada J (2002) Estimates of abundance of northeastern offshore spotted, coastal spotted, and eastern spinner dolphins in the eastern tropical Pacific Ocean. NOAA Admin Rep LJ-02-06

> Gerrodette T, Forcada J (2005) Non-recovery of two spotted and spinner dolphin populations in the eastern tropical Pacific Ocean. Mar Ecol Prog Ser 291:1-21

Gerrodette T, Watters G, Perryman W, Ballance L (2008) Estimates of 2006 dolphin abundance in the eastern tropical Pacific, with revised estimates from 1986-2003. NOAA Tech Memo NMFS-SWFSC-422

Gosliner ML (1999) The tuna-dolphin controversy. In: Twiss JR Jr, Reeves RR (eds) Conservation and management of marine mammals. Smithsonian Institution Press, Washington, DC, p 120-155

Heckel G, Murphy KE, Compeán Jiménez GA (2000) Evasive behavior of spotted and spinner dolphins (Stenella attenuata and $S$. longirostris) during fishing for yellowfin tuna (Thunnus albacares) in the eastern Pacific Ocean. Fish Bull 98:692-703

Hedgepeth JB (1985) Database for dolphin tagging operations in the eastern tropical Pacific, 1969-1978, with discussion of 1978 tagging results. NOAA Admin Rep LJ-85-03

IATTC (Inter-American Tropical Tuna Commission) (2009) Annual report of the Inter-American Tropical Tuna Commission 2007. IATTC, La Jolla, CA

Kinzey D, Olson P, Gerrodette T (2000) Marine mammal data collection procedures on research ship line-transect surveys by the Southwest Fisheries Science Center. NOAA Admin Rep LJ-00-08

Lennert-Cody CE, Scott MD (2005) Spotted dolphin evasive response in relation to fishing effort. Mar Mamm Sci 21: $13-28$ 
Mesnick SL, Archer FI, Allen AC, Dizon AE (2002) Evasive behavior of eastern tropical Pacific dolphins relative to effort by the tuna purse seine fishery. NOAA Admin Report LJ-02-30

National Research Council (1992) Dolphins and the tuna industry. National Academy Press, Washington, DC

Nowacek DP, Thorne LH, Johnston DW, Tyack PL (2007) Responses of cetaceans to anthropogenic noise. Mammal Rev 37:81-115

Okubo A (1980) Diffusion and ecological problems: mathematical models. Springer Verlag, New York, NY

Perkins PC, Edwards EF (1999) Capture rate as a function of school size in pantropical spotted dolphins, Stenella attenuata, in the eastern tropical Pacific Ocean. Fish Bull 97: $542-554$

Perrin WF (1975) Distribution and differentiation of populations of dolphins of the genus Stenella in the eastern tropical Pacific. J Fish Res Board Can 32:1059-1067

Perrin WF (1990) Subspecies of Stenella longirostris (Mammalia: Cetacea: Delphinidae). Proc Biol Soc Wash 103: 453-463

Perrin WF, Henderson JR (1984) Growth and reproductive rates in two populations of spinner dolphins, Stenella longirostris, with different histories of exploitation. Rep Int Whaling Comm 6(Spec Issue):417-430

Perrin WF, Evans WE, Holts DB (1979) Movements of pelagic dolphins (Stenella spp.) in the eastern tropical Pacific as indicated by results of tagging, with summary of tagging operations, 1969-76. NOAA Tech Rep NMFS-SSRF-737

Perrin WF, Scott MD, Walker GJ, Cass VL (1985) Review of geographical stocks of tropical dolphins (Stenella spp. and

Editorial responsibility: Steve Dawson,

Dunedin, New Zealand
Delphinus delphis) in the eastern Pacific. NOAA Tech Rep NMFS-28

Pielou EC (1969) An introduction to mathematical ecology. Wiley-Interscience, New York, NY

Pryor K, Norris K (1978) The tuna/porpoise problem: behavioral aspects. Oceanus 21:31-37

Reilly SB, Donahue MA, Gerrodette T, Forney K and others (2005) Report of the scientific research program under the International Dolphin Conservation Program Act. NOAA Tech Memo NMFS-SWFSC-372

> Romano TA, Keogh MJ, Kelly C, Feng P and others (2004) Anthropogenic sound and marine mammal health: measures of the nervous and immune systems before and after intense sound exposure. Can J Fish Aquat Sci 61:1124-1134

Schramm Urrutia Y (1997) Activity level of offshore spotted (Stenella attenuata) and eastern spinner dolphins (S. longirostris), during tuna purse seining in the eastern Pacific Ocean. MS thesis, Universidad Autónoma de Baja California, Ensenada

Scott MD, Cattanach KL (1998) Diel patterns in aggregations of pelagic dolphins and tuna in the eastern Pacific. Mar Mamm Sci 14:401-428

Scott MD, Chivers SJ (2009) Movements and diving behavior of pelagic spotted dolphins. Mar Mamm Sci 25:137-160

Wade PR (1994) Revised estimates of incidental kill of dolphins (Delphinidae) by the purse seine tuna fishery in the eastern tropical Pacific, 1959-1972. Fish Bull 93:345-354

Wade PR, Reilly SB, Gerrodette T (2002) Assessment of the population dynamics of the northeastern offshore spotted and the eastern spinner dolphin populations through 2002. NOAA Admin Rep LJ-02-13

Submitted: December 22, 2009; Accepted: April 28, 2010 Proofs received from author(s): June 21, 2010 